\title{
ACE-FTS version 3.0 data set: validation and data processing update
}

\author{
Claire Waymark ${ }^{1}$, Kaley A. Walker ${ }^{1,2, *}$, Chris D. Boone ${ }^{2}$, And Peter F. Bernath ${ }^{3,4}$ \\ ${ }^{1}$ Department of Physics, University of Toronto, Toronto, Canada \\ ${ }^{2}$ Department of Chemistry, University of Waterloo, Waterloo, Canada \\ ${ }^{3}$ Department of Chemistry and Biochemistry, Old Dominion University, Norfolk, Virginia, USA \\ ${ }^{4}$ Department of Chemistry, University of York, Heslington, UK
}

\section{INTRODUCTION}

$\mathrm{O}$ n 12 August 2003, the Canadian-led Atmospheric Chemistry Experiment (ACE) was launched into a $74^{\circ}$ inclination orbit at $650 \mathrm{~km}$ with the mission objective to measure atmospheric composition using infrared and UV-visible spectroscopy (Bernath et al., 2005). The ACE mission consists of two main instruments, ACE-FTS and MAESTRO (McElroy et al., 2007), which are being used to investigate the chemistry and dynamics of the Earth's atmosphere. Here, we focus on the high resolution $\left(0.02 \mathrm{~cm}^{-1}\right)$ infrared Fourier Transform Spectrometer, ACE-FTS, that measures in the $750-4400 \mathrm{~cm}^{-1}$ (2.2 to $\left.13.3 \mu \mathrm{m}\right)$ spectral region. This instrument has been making regular solar occultation observations for more than nine years. The current ACE-FTS data version (version 3.0) provides profiles of temperature and volume mixing ratios (VMRs) of more than 30 atmospheric trace gas species, as well as 20 subsidiary isotopologues of the most abundant trace atmospheric constituents over a latitude range of $\sim 85^{\circ} \mathrm{N}$ to $\sim 85^{\circ} \mathrm{S}$. This letter describes the current data version and recent validation comparisons and provides a description of our planned updates for the ACEFTS data set.

\footnotetext{
* Corresponding author: Kaley A. Walker, kwalker@atmosp.physics.utoronto.ca
}

\section{VALIDATION RESULTS}

An extensive validation exercise was undertaken for the ACE-FTS baseline species (VMR profiles of $\mathrm{O}_{3}, \mathrm{H}_{2} \mathrm{O}, \mathrm{CH}_{4}, \mathrm{~N}_{2} \mathrm{O}, \mathrm{NO}_{2}, \mathrm{NO}$, $\mathrm{HNO}_{3}, \mathrm{HCl}, \mathrm{HF}, \mathrm{CO}, \mathrm{CCl}_{3} \mathrm{~F}, \mathrm{CCl}_{2} \mathrm{~F}_{2}, \mathrm{~N}_{2} \mathrm{O}_{5}$, and $\mathrm{ClONO}_{2}$ ) and temperature for the version 2.2 (+updates for $\mathrm{O}_{3}, \mathrm{~N}_{2} \mathrm{O}_{5}$ and HDO) data set. The retrievals for this version have been described in detail in Boone et al. (2005). The validation results were reported in a special issue of Atmos. Chem. Phys. (http://www.atmoschem-phys.net/special_issue114.html). By building on these comparison results, a newer version of the ACE-FTS data set (version 3.0) was produced that incorporated a new set of microwindows and updated spectroscopic parameters. It addressed the unphysical oscillations that were found in the mesospheric temperature profiles and an artefact (or "glitch") that occurred in the temperature profiles near $23 \mathrm{~km}$. In addition, the altitude ranges for nearly all species have been extended. These increases range from a few $\mathrm{km}$ to as much as $35 \mathrm{~km}$ for $\mathrm{N}_{2} \mathrm{O}$. These improvements have been briefly summarized in Table 1 and are documented in Boone et al. (2013).

For the version 3.0 data set, work has been undertaken to characterize the results by performing both comparisons between versions and comparisons with measurements by other satellite instruments. Herein, we focus on describing the direct version comparisons for the 
ANNALS OF GEOPHYSICS, 56, Fast Track-1, 2013; 10.4401 / ag-6339

ACE-FTS baseline species. These comparisons have been carried out in order to identify the changes to the ACE-FTS retrievals between the new version 3.0 and the previous wellvalidated (version 2.2 +updates) data set. The-
These results allow users to understand the data quality of the version 3.0 data set in relation to the earlier validation studies for the version $2.2+$ updates data set.

Table 1: Summary of the processing differences between ACE-FTS v2.2 and v3.0.

\begin{tabular}{|c|c|}
\hline Retrieval parameter & Version 3.0 (v3.0) versus Version 2.2+Updates (v2.2) \\
\hline Altitu & $\begin{array}{l}\text { Ranges increased for most species by a few } \mathrm{km} \text { up to } \sim 35 \mathrm{~km} \text { for } \mathrm{N}_{2} \mathrm{O} \text {. } \\
\text { Upper altitude limits that varied with latitude were employed for some } \\
\text { molecules in v3.0. }\end{array}$ \\
\hline Microv & $\begin{array}{l}\text { Updated to new set for all species, typically using more microwindows } \\
\text { in v3.0 to improve the information content on the target constituent. }\end{array}$ \\
\hline VMR retrieval & $\begin{array}{l}\text { Isotopologues can be treated as separate molecules, i.e., each iso- } \\
\text { topologue serving as an interferer in a retrieval has an independent } \\
\text { VMR profile. In v2.2, different isotopologues of the same molecule } \\
\text { were assumed to have the same VMR profile. }\end{array}$ \\
\hline Spectral line list & Updated line list using HITRAN 2004 with se \\
\hline $\begin{array}{l}\text { Routinely processed } \\
\text { species }\end{array}$ & $\begin{array}{l}\text { Number of species routinely processed increased to include COClF, } \\
\mathrm{COCl}_{2}, \mathrm{O}_{2}, \mathrm{H}_{2} \mathrm{CO}, \mathrm{CH}_{3} \mathrm{OH} \text { and } \mathrm{HCFC}-141 \mathrm{~b} \text {, as well as a number of ad- } \\
\text { ditional subsidiary isotopologues: }{ }^{18} \mathrm{O}^{12} \mathrm{C}^{16} \mathrm{O},{ }^{17} \mathrm{O}^{12} \mathrm{C}^{16} \mathrm{O},{ }^{18} \mathrm{O}^{13} \mathrm{C}^{16} \mathrm{O} \text {, } \\
{ }^{18} \mathrm{O}^{16} \mathrm{O}^{16} \mathrm{O},{ }^{16} \mathrm{O}^{18} \mathrm{O}^{16} \mathrm{O},{ }^{16} \mathrm{O}^{17} \mathrm{O}^{16} \mathrm{O} \text {, N } 2{ }^{18} \mathrm{O}, \mathrm{OC}^{34} \mathrm{~S} \text {, and } \mathrm{O}^{13} \mathrm{CS}\end{array}$ \\
\hline $\begin{array}{l}\text { Empirical function in } \\
\text { ILS calculation }\end{array}$ & $\begin{array}{l}\text { A new empirical function was used to characterize the ACE-FTS's self } \\
\text { apodization, one which yielded improved residuals compared to v2.2. }\end{array}$ \\
\hline $\begin{array}{l}\text { Temperature interpola- } \\
\text { tion in } \mathrm{P} / \mathrm{T} \text { retrieval }\end{array}$ & $\begin{array}{l}\text { Altitude interpolation approach for temperature was changed to match } \\
\text { what was used for VMR retrieval. This fixed the unphysical oscilla- } \\
\text { tions observed in v2.2 temperature profiles. }\end{array}$ \\
\hline Issue at $\sim 23 \mathrm{~km}$ & $\begin{array}{l}\text { No empirical function is used in the retrieval of pressure below } 23 \mathrm{~km} \\
\text { in v3.0; pressure at each analysed measurement is used as a fitting pa- } \\
\text { rameter }\end{array}$ \\
\hline $\begin{array}{l}\text { Altitude lower limit in } \\
\mathrm{P} / \mathrm{T} \text { retrieval }\end{array}$ & Changed from $12 \mathrm{~km}$ (v2.2) to $15 \mathrm{~km}$ (v3.0) \\
\hline $\begin{array}{l}\text { High altitude retrieval } \\
\text { in } \mathrm{P} / \mathrm{T} \text { retrieval }\end{array}$ & $\begin{array}{l}\text { The retrieved } \mathrm{CO}_{2} \mathrm{VMR} \text { profile at high altitudes was forced to match } \\
\text { fixed } \mathrm{CO}_{2} \mathrm{VMR} \text { at the interface (near } 60 \mathrm{~km} \text { ) }\end{array}$ \\
\hline $\begin{array}{l}\text { Tangent height separa- } \\
\text { tion in } \mathrm{P} / \mathrm{T} \text { retrieval }\end{array}$ & $\begin{array}{l}\text { The tangent height separation is calculated in a way that improves the } \\
\text { stability of the retrieval compared to v2.2 }\end{array}$ \\
\hline
\end{tabular}


The comparison approach taken for this work follows the method described by Dupuy et al. (2009). Rather than finding pairs of "coincident" measurements by different instruments, the pairs used here are all ACE-FTS occultations for which profiles are available for both data versions. For each trace gas species (or subset of these data), the mean profiles and 1- $\sigma$ standard deviation of the mean are calculated for each data version. The absolute and relative differences are calculated from individual pairs of profiles and then the means of these differences are calculated (see Eqs. 3 and 4, respectively, in Dupuy et al., 2009). To calculate the relative differences, the mean of the version 2.2+updates and version 3.0 VMR is used as the denominator. As was done for most of the version $2.2+$ updates validation studies, the standard deviation of the bias-corrected differences (which will be referred to as the "debiased standard deviation") is calculated for these comparisons (e.g. Eq. 5 in Dupuy et al., 2009). This gives a measure of the combined precision of the two ACE-FTS data versions (von Clarmann 2006). For the results shown here, no data screening has been applied in order to examine all of the profiles produced for the two ACE-FTS data versions.

The ACE-FTS measurements made between 21 February 2004 (beginning of routine operations) and 30 September 2010 have been used in this work. This analysis has been performed for the full latitude range as well as for selected latitude bands (typically using $30^{\circ}$ bins) for all fourteen of the ACE-FTS baseline species. An example of the direct version comparisons for $\mathrm{O}_{3}$ is shown in Figure 1 for the latitude band between $30^{\circ} \mathrm{S}$ and $60^{\circ} \mathrm{S}$. The results shown here are consistent with those seen in all of the different latitude bands. Figure 2 shows two additional examples of these direct version comparisons for $\mathrm{CH}_{4}$ and $\mathrm{H}_{2} \mathrm{O}$.

In addition to subdividing the data into various latitude bands, the data have also been compared separately for different time periods. Figure 3 shows an example for $\mathrm{O}_{3}$ where the relative differences for each year are calculated separately to examine the year-to-year

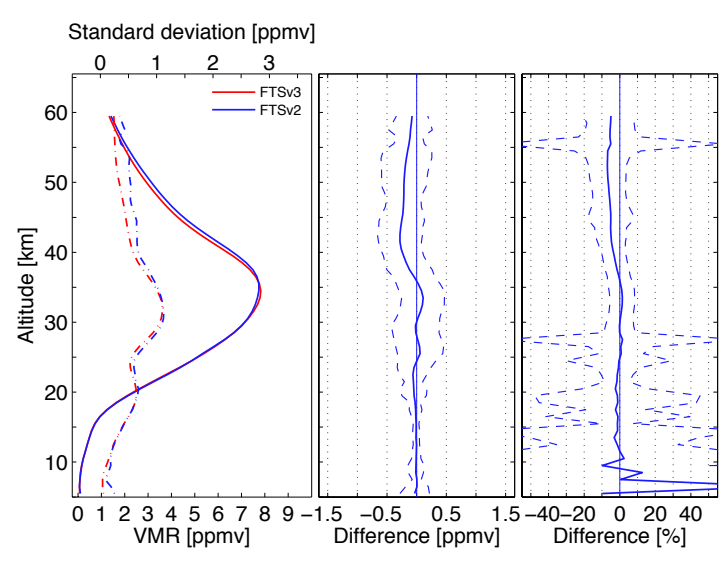

Figure 1: An example of the ACE-FTS direct version comparisons for $\mathrm{O}_{3}$ for the $30-60^{\circ} \mathrm{S}$ latitude range. This compares the version $2.2 \mathrm{O}_{3}$ update (blue) product with the version 3.0 (red) product. The mean VMR profiles (solid lines) and the 1- $\sigma$ standard deviations (dot-dashed lines) are shown in the left panel, the absolute differences are shown in the centre panel and the relative differences are shown in the right panel. The dashed lines in the centre and right panels indicate the de-biased standard deviation of the mean differences.

changes. It can be seen that these differences are quite consistent for most years, with all years seeing quite large variability below $\sim 20$ $\mathrm{km}$. However, above $\sim 20 \mathrm{~km}, 2008$ has larger variability than the other years as shown in the de-biased standard deviation of the mean difference. This is primarily due to increased numbers of outlier profiles, which we are currently in the process of characterizing to understand their origin and to provide guidance to users to allow these to be filtered out as needed. A list of occulations with known issues is provided by the ACE Science Operations Centre (https:/ / databace.scisat.ca/validation/data_is sues.php). In addition to consulting this list, users are encouraged to submit reports the ACE team outlining any issues they find.

A summary of the results obtained for the direct version comparisons of the ACE-FTS baseline species is shown in Table 2. For each species, the reference describing the version $2.2+$ updates validation study and the altitude range for the version 3.0 retrievals are listed. 

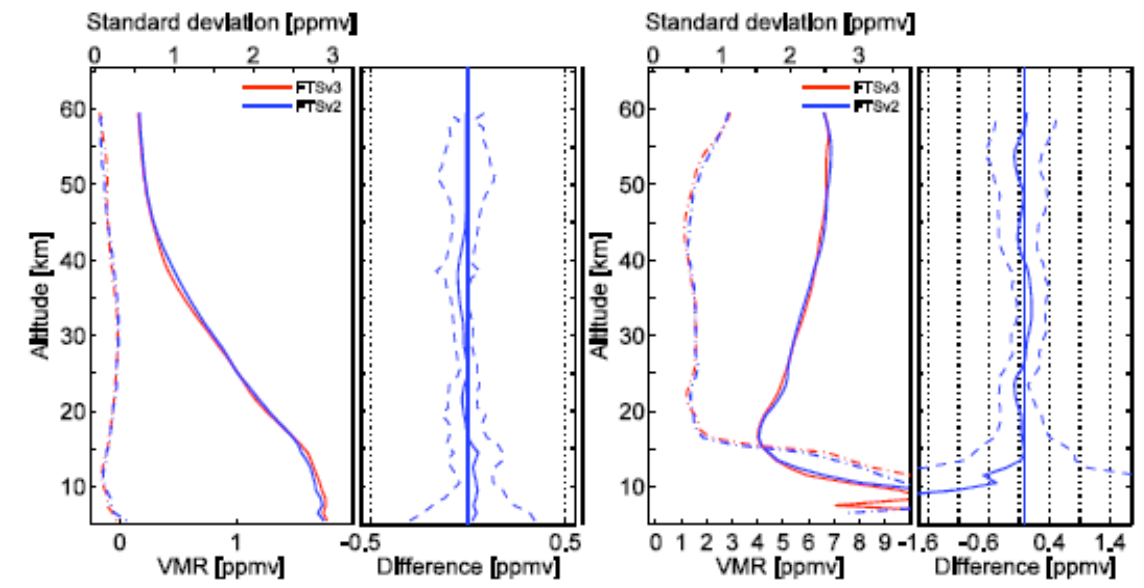

Figure 2: Two further examples of version 2.2 versus version 3.0 comparisons (mean profiles and absolute differences) for $\mathrm{CH}_{4}$ (left panels) and $\mathrm{H}_{2} \mathrm{O}$ (right panels). The legend for each pair of panels is the same as given for the corresponding panel in Fig. 1. Measurements from all latitudes are included in these comparisons.

In addition, brief summaries of the version $2.2+$ updates validation results are given in Jones et al. (2012). The differences described for the version 3.0 data set, compared to version $2.2+$ updates, are consistent with the need to reduce the bias seen in the version
$2.2+$ updates validation studies. A more detailed validation paper is in preparation in which the ACE-FTS v3.0 dataset is compared to the ACE-FTS v2.2+updates dataset as well as several other satellites (SAGE II, SAGE III, POAM III, HALOE, OSIRIS and MLS).
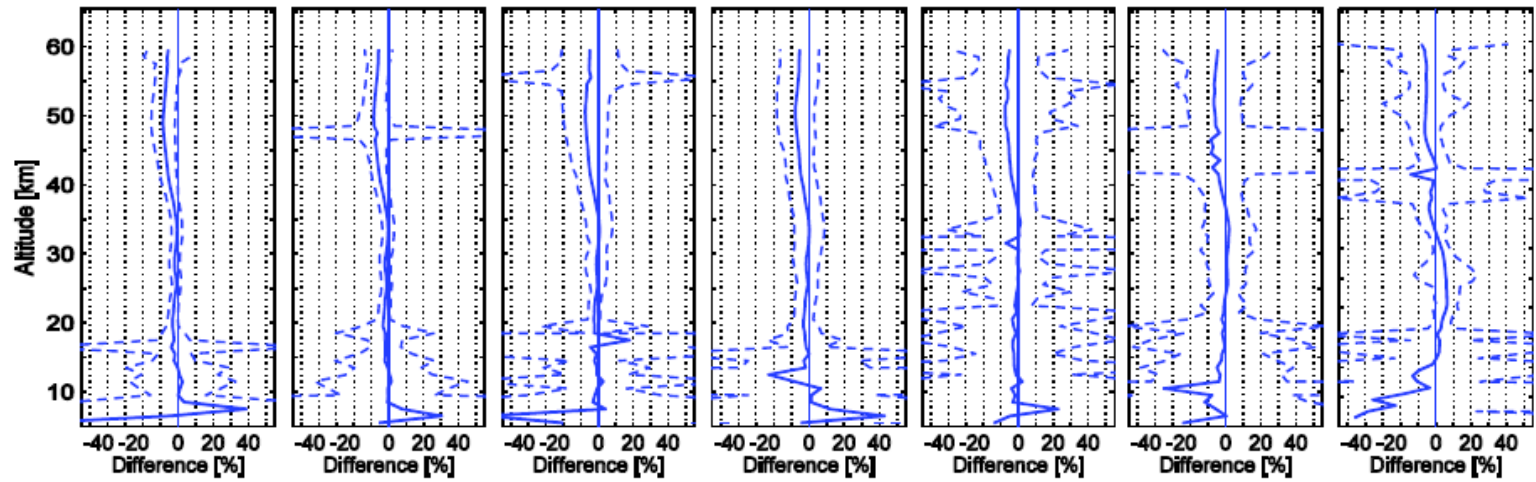

Figure 3: The mean relative differences for the direct version comparisons for $\mathrm{O}_{3}$ are shown for each year from 2004 (far left) to 2010 (far right). 
ANNALS OF GEOPHYSICS, 56, Fast Track-1, 2013; 10.4401 / ag-6339

Table 2: Summary of the version 2.2+updates and version 3.0 direct version comparisons.

\begin{tabular}{|c|c|c|c|}
\hline Molecule & $\begin{array}{c}\text { Altitude } \\
\text { Range }(\mathrm{km})\end{array}$ & $\begin{array}{l}\text { Comparison Result (behavior of version } \\
3.0 \text { relative to version } 2.2+\text { updates) }\end{array}$ & $\begin{array}{l}\text { Previous Validation } \\
\text { Results (Version 2.2) }\end{array}$ \\
\hline $\mathrm{O}_{3}$ & $5-95$ & $\begin{array}{l}\text { A reduction of } \sim 5 \% \text { is seen above the } \\
\text { peak, at } \sim 35 \mathrm{~km} \text { and higher altitudes. }\end{array}$ & $\begin{array}{l}\text { Dupuy et al. (2009) } \\
\text { (version } 2.2 \mathrm{O}_{3} \text { update) }\end{array}$ \\
\hline $\mathrm{CH}_{4}$ & $5-62$ & $\begin{array}{l}\text { A reduction of } \sim 10 \% \text { is seen near } \sim 35-40 \\
\mathrm{~km} \text { and slight reduction is seen at } \sim 23 \mathrm{~km} \text {. }\end{array}$ & De Mazière et al. (2008) \\
\hline $\mathrm{H}_{2} \mathrm{O}$ & $5-89$ & $\begin{array}{l}\text { Small differences of } \sim \pm 2 \% \text { are seen over } \\
\text { the altitude range between } \sim 20 \text { and } \sim 55 \\
\mathrm{~km}\end{array}$ & Carleer et al. (2008) \\
\hline NO & 12-105 & $\begin{array}{l}\text { A slight increase of } \sim 2 \% \text { is seen between } \\
\sim 25 \text { and } \sim 40 \mathrm{~km} \text { and reduction of } \sim 2 \% \text { is } \\
\text { seen above } \sim 40 \mathrm{~km} .\end{array}$ & $\begin{array}{l}\text { Kerzenmacher et al. } \\
(2008)\end{array}$ \\
\hline $\mathrm{N}_{2} \mathrm{O}$ & $5-60$ & A reduction of $\sim 10 \%$ is seen above $\sim 35 \mathrm{~km}$ & Strong et al. (2008) \\
\hline $\mathrm{NO}_{2}$ & $13-45$ & $\begin{array}{l}\text { A reduction of } \sim 10 \% \text { is seen in the altitude } \\
\text { range of } \sim 40-45 \mathrm{~km} \text {. }\end{array}$ & $\begin{array}{l}\text { Kerzenmacher et al. } \\
(2008)\end{array}$ \\
\hline $\mathrm{N}_{2} \mathrm{O}_{5}$ & $15-40$ & $\begin{array}{l}\text { Above } \sim 20 \mathrm{~km} \text {, an increase is seen that is } \\
\mathrm{up} \text { to } \sim 0.04 \mathrm{ppbv} \text { at } \sim 26-30 \mathrm{~km} \text {. Below } \sim 20 \\
\mathrm{~km} \text {, a reduction is seen that is up to } \sim 0.035 \\
\text { ppbv at } \sim 15 \mathrm{~km} .\end{array}$ & $\begin{array}{l}\text { Wolff et al. (2008) } \\
\text { (version } 2.2 \mathrm{~N}_{2} \mathrm{O}_{5} \text { up- } \\
\text { date) }\end{array}$ \\
\hline $\mathrm{HF}$ & $10-50$ & A reduction of $\sim 5 \%$ is seen over profile. & Mahieu et al. (2008) \\
\hline $\mathrm{HCl}$ & $8-57$ & A reduction of $\sim 5 \%$ is seen over profile & Mahieu et al. (2008) \\
\hline $\mathrm{CCl}_{3} \mathrm{~F}$ & $2-22$ & A slight increase is seen around $\sim 15 \mathrm{~km}$. & Mahieu et al. (2008) \\
\hline $\mathrm{CCl}_{2} \mathrm{~F}_{2}$ & $6-28$ & $\begin{array}{l}\text { An increase of } \sim 2-5 \% \text { is seen over the } \\
\sim 6-22 \mathrm{~km} \text { altitude range. }\end{array}$ & Mahieu et al. (2008) \\
\hline $\mathrm{ClONO}_{2}$ & $12-35$ & $\begin{array}{l}\text { From } \sim 17-22 \mathrm{~km}, \text { a } \sim 20-30 \% \text { reduction is } \\
\text { seen. A } \sim 7 \% \text { reduction was also seen } \\
\text { above the peak, at } \sim 30-32 \mathrm{~km} \text {. }\end{array}$ & Wolff et al. (2008) \\
\hline $\mathrm{CO}$ & $5-105$ & $\begin{array}{l}\text { Below } \sim 10 \mathrm{~km} \text { and between } \sim 35 \text { and } \\
\sim 45 \mathrm{~km} \text {, a small decrease is seen. Between } \\
\sim 14 \text { and } \sim 18 \mathrm{~km} \text {, a small increase is seen. }\end{array}$ & Clerbaux et al. (2008) \\
\hline $\mathrm{HNO}_{3}$ & $5-37$ & Above $\sim 25 \mathrm{~km}$, an increase of $\sim 5 \%$ is seen. & Wolff et al. (2008) \\
\hline
\end{tabular}




\section{ACE-FTS Processing Plans}

The next processing version (version 4.0) is now in development (Boone et al., 2013). The primary motivation for this update is to develop a data set that is more appropriate for studying longer-term changes and investigating trends. In ACE-FTS processing versions 3.0 and earlier, the assumed rate of change in $\mathrm{CO}_{2}$ as a function of time is too low and will therefore be changed to match better with observations. In version 4.0 , the shape of the $\mathrm{CO}_{2}$ VMR profiles at low altitudes will vary with latitude, and a seasonal cycle will be included, features that were not present in previous processing versions.

An issue was identified in the input a priori temperature/pressure profiles for low altitudes that has affected all ACE-FTS retrievals beginning in October 2010 (Boone et al., 2013). Because of this, data from both version $2.2+$ updates and version 3.0 should not be used after 30 September 2010. New processing versions (2.5 and 3.5) are being produced to provide corrected results for the affected time period (October 2010 onward). These new versions do not include any changes in the retrieval process other than employing more appropriate a priori pressure and temperature information (Boone et al., 2013).

\section{CONCLUSION}

ACE-FTS and the SCISAT satellite continue to perform well in their tenth year in orbit and produce a valuable data set for investigating the composition of the Earth's atmosphere. Through direct profile comparisons, the current ACE-FTS v3.0 data set is generally seen to improve on the v2.2+updates data set. Comparisons with other satellite data sets are in progress and these results are being used to provide feedback for future ACE-FTS data versions.

\section{ACKNOWLEDGEMENTS}

Funding for ACE is provided mainly by the Canadian Space Agency (CSA) and the Natural Sciences and Engineering Research Council of Canada. This work was supported by the CSA.

\section{REFERENCES}

[Bernath et al., 2005] Bernath, P.F., et al. (2005). Atmospheric Chemistry Experiment (ACE): Mission Overview, Geophys. Res. Lett., 32:L15S01.

[Boone et al., 2008] Boone, C. D. et al. (2008). Retrievals for the Atmospheric Chemistry Experiment Fourier Transform Spectrometer, Appl. Optics, 44:7218-7231.

[Boone at al., 1013] Boone, C. D. et al. (2013). Version 3 Retrievals for the Atmospheric Chemistry Experiment Fourier Transform Spectrometer (ACE-FTS) in The Atmospheric Chemistry Experiment ACE at 10: A Solar Occultation Anthology, Peter F. Bernath (Editor), A. Deepak Publishing, Hampton, Virginia.

[Carleer et al., 2008] Carleer, M.R., et al. (2008). Validation of water vapour profiles from the Atmospheric Chemistry Experiment (ACE), Atmos. Chem. Phys. Discuss., 8:4499-4559.

[Clerbaux et al., 2008] Clerbaux, C., et al. (2008). CO measurements from the ACE-FTS satellite instrument: data analysis and validation using ground-based, airborne and spaceborne observations, Atmos. Chem. Phys., 8:2569-2594.

[De Mazière et al., 2008] De Mazière, M., et al. (2008). Validation of ACE-FTS v2.2 methane profiles from the upper troposphere to lower mesosphere, Atmos. Chem. Phys., 8:2421-2435.

[Dupuy et al., 2009] Dupuy, E., et al. (2009). Validation of ozone measurements from the Atmospheric Chemistry Experiment (ACE), Atmos. Chem. Phys., 9:287-343.

[Jones et al., 2012] Jones, A. et al. (2012). Technical Note: A trace gas climatology de- 
rived from the Atmospheric Chemistry Experiment Fourier Transform Spectrometer dataset, Atmos. Chem. Phys., 12:5207-5220. [Kerzenmacher et al., 2008] Kerzenmacher, T., et al. (2008). Validation of $\mathrm{NO}_{2}$ and $\mathrm{NO}$ from the Atmospheric Chemistry Experiment (ACE), Atmos. Chem. Phys., 8:58015841.

[Mahieu et al., 2008] Mahieu, E., et al. (2008). Validation of ACE-FTS v2.2 Measurements of $\mathrm{HCl}, \mathrm{HF}, \mathrm{CCl}_{3} \mathrm{~F}$, and $\mathrm{CCl}_{2} \mathrm{~F}_{2}$ using space-, balloon- and ground-based instrument observations. Atmos Chem Phys, 8:6199-6221.

[McElroy et al., 2007] McElroy, C.T., et al. (2007). The ACE-MAESTRO Instrument on
SCISAT: description, performance and preliminary results, Appl. Opt., 46:4341-4356 [Strong et al., 2008] Strong, K., et al. (2008). Validation of ACE-FTS $\mathrm{N}_{2} \mathrm{O}$ measurements. Atmos. Chem. Phys., 8:4759-4786. [von Clarmann et al., 2006] von Clarmann, T. (2006). Validation of remotely sensed profiles of atmospheric state variables: strategies and terminology, Atmos. Chem. Phys., 6:4311-4320.

[Wolff et al., 2008] Wolff, M.A., et al. (2008). Validation of $\mathrm{HNO}_{3}, \mathrm{ClONO}_{2}$, and $\mathrm{N}_{2} \mathrm{O}_{5}$ from the Atmospheric Chemistry Experiment Fourier Transform Spectrometer (ACEFTS), Atmos. Chem. Phys., 8:3529-3562. 